\title{
Modeling, Simulation and Validation of a Tractor Wet Clutch Controlled by Proportional Valve
}

\author{
Ali Evren Yel $^{1}$, Haydar Livatyali ${ }^{2, *}$ \\ 0000-0003-3136-5742 $2^{1}, 0000-0002-9542-2390^{2}$
}

${ }^{1}$ TÜMOSAN Corp., Cevizlibağ, Istanbul, Turkey

${ }^{2}$ Yıldız Technical University, Dept. of Mechatronics Engr., Beşiktaş, Istanbul, Turkey

\section{Abstract}

Wet clutch is a widely used machine element in the agricultural machines because it allows the transmission of high torque with a more user-friendly turn on/off. In this article, the control of a wet clutch pack using a proportional valve in the power take-off unit is investigated. A wet clutch package is implemented on the transmission direct PTO shaft and actuate the power take-off unit of an agricultural tractor. A one-dimensional mathematical model of the wet clutch and the electro-hydraulic control system was developed. Several actuation cases were simulated, and responses of all circuit elements were evaluated. Based on these predictions, test procedures without-put torque values 300 and 600 $\mathrm{N}-\mathrm{m}$ were set at $1.900 \mathrm{rpm}$ unloaded engine speed. Variables, including speed, pressure, and temperature, were recorded in the experiments. The test and simulation results were compared. The clutch pressure increase was $10 \%$ under-predicted while the mainline pressure drop was $1 \%$ over-predicted. The proposed 1-D model can be further improved indeed. Yet, the acceptable agreement between the model and tests, offer less costly trialand-error in the design and tune-up of future systems.

Keywords: Power Transmission, Wet Clutch, Hydraulics Modeling, PWM based control

\section{Research Article}

http://doi.org/10.30939/ijatech..797276

Received $\quad 19.09 .2020$

Revised $\quad 05.12 .2020$

Accepted $\quad 07.12 .2020$

* Corresponding author

Haydar Livatyalı

hlivatya@yildiz.edu.tr

Address: Yildiz Technical Unv. Dept. of Mechatronics Engr.

Beşiktaş, Istanbul, TR-34349

Turkey

Tel: +90-212-383 2888

\section{Background and Objectives}

Wet clutches are being used more than ever in highway, agricultural, and construction vehicles as well as mining machinery, marine power and maneuvering systems, textile and packaging machines, presses, machine tools, and other production machines to transfer power and torque. The general advantages of wet clutches include a low moment of inertia, small application volumes, high power/weight ratio, large torque capacity, high torque in modular design, high-temperature capacity, high strength and reliability, and excellent controllability [1].

Due to its high torque carrying capacity and ease of use, wet clutches are preferred in tractor tail shafts in recent years to power auxiliary equipment. When wet clutches are compared to dry clutches, their dimensions, torque carrying capacities, heat removal, and temperature control make their functional lifetime much longer [2]. Their functioning is influenced by variables such as the load, transmission fluid temperature, engine torque, and power. The fluid pressure must be controlled during engagement and disengagement, and the hydraulic system must operate precisely and swiftly. To use an electro-hydraulic proportional valve and to maintain the pressure constant behind the valve, the pressure relief valves must work in harmony. The proportional valve must be controlled by a controller that exhibits a stable behavior. If the specified variables are ignored, the friction elements in the clutch, such as the friction discs, wear out quickly due to sliding friction, reduce the life span and lead to failure in brief periods (Fig. 1).

In this paper, the design of a new wet clutch for the actuation of the power take-off (PTO) unit in the transmission of an agricultural machine is shared. The objective is to design an electro-hydraulic system for optimum engagement of the PTO output using a wet clutch and to develop a practical and effective method for the design and analysis of future models. A one-dimensional mathematical model of the wet clutch and electro-hydraulic control system was developed. After modeling the designed concept and a series of simulations, the results were verified by a limited number of tests. Variations of pressure and shaft speed were investigated in terms of the retarding torque. Various actuation cases of the electro-hydraulic circuit were simulated, and the results are evaluated.

\section{Design of Wet Clutches}

Wet clutch systems are mostly laminated and multi-plate. The total area of the friction surface is increased by increasing the number of 


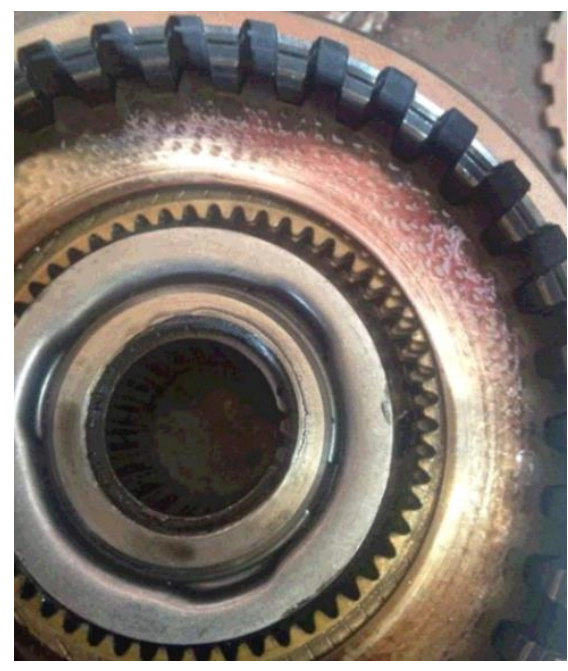

Fig. 1. A damaged friction disc due to long-term sliding and friction

friction surfaces (pressure plates and clutch discs), thus improving the torque capacity to be transferred. Wet clutches have a high level of comfort during engaging and disengaging. They have a long life compared to the dry clutches due to the high number of friction surfaces and active lubrication. The transmission fluid reduces the friction coefficient between the clutch disc and pressure plates significantly. The transmission fluid removes the heat released by friction, and the latter must be cooled afterward. The significant advantage of temperature control is that variation of the friction coefficient is much less compared to the dry clutch. Since they work in oil, spiral, oblique, or cross grooves should be opened to prevent the plates from sticking together [3].

Fig. 2 shows the schematic of a typical multi-plate wet clutch. The hydraulic fluid is fed to the piston unit to create pressure in the chamber. Thus, the piston applies pressure to the steel plate, and all the plates are compressed with the normal force produced the cylinder, and the required moment is transferred from the input shaft to the output shaft. Return spring pushes the piston to the initial position with the fluid evacuation.

The coefficient of friction in a wet clutch is a function of the sliding speed as well as friction disc materials, surface pressure and temperature with positive and negative gradients. The curve given by Fischer et al. indicates the reduction of friction coefficient with increasing temperature [4]. Fortunately, the friction coefficient stabilizes at higher temperatures and high shear rates.

When the two common friction disc materials, sintered bronze, and paper-based disc, are compared as alternatives, the coefficient of friction of the paper-based one increases depending on the shear rate, and its performance is stable without any decrease concerning speed [4]. The elasticity modulus of the friction disc material has a significant influence on the pressure distribution on it. At the same time, the shear stress on the disc affects mechanical durability, and sintered bronze based discs have a longer life in that respect. The friction coefficient also depends on the differential speed, and it may fluctuate between 0.05 and 0.4 [5].

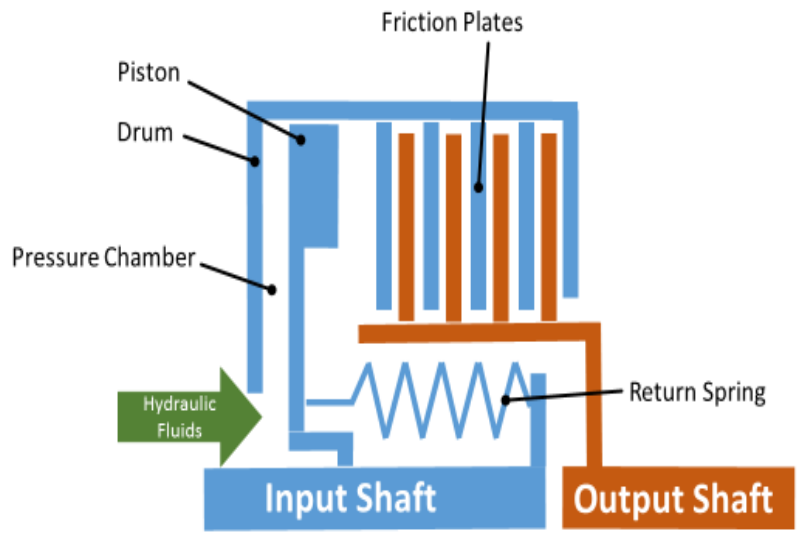

Fig. 2. Schematic overview of a typical multi-plate wet clutch

A pressure reducing proportional valve (PRPV) is used to control the multi-plate wet clutch presented in this article, and these valves are controlled by pulse width modulation (PWM). The relationships between the actuator and the clutch system and between the inlet and the outlets have been analyzed by a detailed model based on the valve controlling the wet clutch and the flow dynamics in the wet clutch pack.

In such systems, the predicted dynamic behavior varies considerably, mainly due to the detail level of the proportional valve model and the temperature-dependent oil viscosity $[6,7]$. The oil temperature, which is equal to the ambient temperature at the initial start of the tractor, may reach $110^{\circ} \mathrm{C}$ depending on the operating conditions, internal combustion engine (ICE) speed, and the type of tractor attachment. Therefore, consistent oil temperature will bring comfort to the user. The pressure drop due to increased temperature is experimentally shown to reduce the performance [8].

The inspiration for using the pressure reducing control valves in wet clutches comes from the fuel injection systems. Using the power oriented graph technique, a method similar to the Bond graph, the system, and valves were modeled in detail [7]. As a result, fast and slow dynamic actuator and valve movements were correlated with test results, and it was observed that a small mechanical change on the valve had an apparent effect on the system performance. In some research, the control strategies were based on the non-linear dynamic behavior of multi-plate wet clutch groups during commissioning.

A two level controller is developed to reduce the control complexity. Two Level Non-Linear Model Predictive Controller (2L-NMPC) and Two Level Iterative Learning Controller (2LILC) methods are implemented for the clutch control. Both methods have pros and cons. In terms of convergence time, $2 \mathrm{~L}$ ILC is worse than 2L-NMPC. On the other hand, in terms of tracking performance 2L-ILC is proven better [9]. The use of iterative learning controllers and non-linear system controllers (N-mPC) in wet multi-plate systems was demonstrated successfully. 
The engagement times of the wet multi-plate clutches in tractors as well as front and backhoe loaders are optimized by adjusting modulation ramps for the forward and reverse travel. Mathematical modeling of both the mechanical parts and the electro-hydraulic control system is performed to make this improvement [10].

The effects of design parameters on wet-slide forwardbackward shuttle systems on a tractor reveal that gear quality is a first-order function of the pressure modulation [11]. The peak torque and the normal clutch force increase with increasing tractor speed. It is predicted that the $20 \%$ faster reverse gear gives a better gear shift performance than the forward clutch group. The weight of the tractor does not affect the power that the unit area of the clutch can transmit, and the damping element does not decrease the input torque peak values, but it prevents fluctuation of it.

Various methods are proposed for the control of wet clutches. These methods are divided into two groups; model-based and model-free. The example of model-based control is Nonlinear Model Predictive Control (NMPC), Iterative Learning Control (ILC) and Iterative Optimization (IO) and the example of model-free control is Genetic-based Machine Learning (GA) and Reinforcement Learning (RL). To be compared each other in terms of engagement time and jerk; model-based methods behave similarly. Among the model-free methods; RL is slightly better than GA. Converging time of the Model-based methods is shorter than the Model-Free methods. On the other hand, ModelFree method is appropriate for the more complex mechatronic system to optimize parameters [12].

Dissipated kinetic and potential energy will be transferred into to heat when the clutch activated. Surface of brakes/clutches might be damaged if cooling performance is not well enough to compensate the dissipated energy. The bidirectional thermalstructure coupling method can be applied for finding better solution of this problem [13].

Detailed mathematical model set up for direct acting solenoid valve and wet clutch piston to analyze effects of whole system. There is contradiction between high flow rate and pressure accuracy. Force balancing is proven as the key factor to manage this problem [14].

All parameters such as load, oil temperature, and amount of wear can change over time. That's why nonlinear behavior is the challenging nature of wet clutch control [15].

\section{Mathematical Model}

Due to the multi-physical nature of the technical problem, the model proposed has been developed in the SimCenter Amesim software, where complex systems can be modeled in a simplified one-dimensional structure [17]. To solve this problem, which includes mechanical, hydraulic, and control aspects, all sub-parts have been modeled in detail, and dynamic transient analyses have been performed. This model simulates the effects of the hydraulic fluid pressure and flow rate as a function of time (by the controller signal) to the wet clutch behavior.

\subsection{Mechanical System}

The mechanical system is located inside the transmission housing (Fig. 2), and it takes the input power from the ICE and transfers it to the tail shaft. Mechanical and hydraulic elements include the transmission shaft, clutch body, separator disc, clutch piston, main disc, transmission fluid, and the flywheel (Fig. 3). On the front and back sides of the main disc, the friction disc is coated by a friction material.

The wet clutch is a hydro-mechanical system operating under pressure. The rotating piston, piston seals, piston mass, spring pushing the piston, and the whole clutch pack are modeled as individual units. The mainline pressure is connected to the Port$\mathrm{P}$ of the proportional valve (Fig. 4). When activation of the wet clutch is required, the PWM (pulse width modulation) signal is sent to the solenoid valve and utilizing the pilot control volume of the valve, and it is possible to pass pressure to Port-2, the user output. After the pressure is applied to the clutch cylinder, the piston moves and compresses the friction discs onto the thrust plates, and the engagement is completed. Since the cylinder is on the engine side, it continuously rotates at the same speed as the engine. The pressurized oil coming from the PPRV valve fills the initially vacant (dead) volume, and the pressure increases with time. In the piston model, Track-3 is the path through which the hydraulic fluid passes and forms the clutch pressure (Fig. 5). From Track-1, the speed determines the moment, and from Track-4, the opposite torque is applied. A drain hole on the clutch open to ambient is used for lubrication and is modeled as a hydraulic damper. Piston seal, piston mass, and return spring are included in the model. The effective area of the piston determines the net force on the clutch plates; therefore, piston inner and the outer regions are factored with pressure. The centrifugal force of the pressurized fluid in the rotating volume induces an extra force on the piston. Although this value corresponds to approximately $1 \%$ of the total force, adding it to the model improves the accuracy of the model.

$V_{\text {oil }}(t)=V_{\text {oil }}(0)+\int_{0}^{t}\left(q_{1}+q_{3}\right) d t$

Where $A_{P}$ and $V_{p v 0}$ refer to the active piston area and the cylinder dead volume, respectively. When calculating the piston volume, the piston speed $v_{4}$ is found by integrating and adding to the initial volume.

$V_{p v}(t)=V_{p v 0}+\int_{0}^{t} v_{4} \cdot A_{P} d t$

Assuming that the volume is constant and the oil incompressible, the oil volume is equal to the cylinder volume. Therefore, the initial cylinder dead volume $V_{p v 0}$ is smaller than 


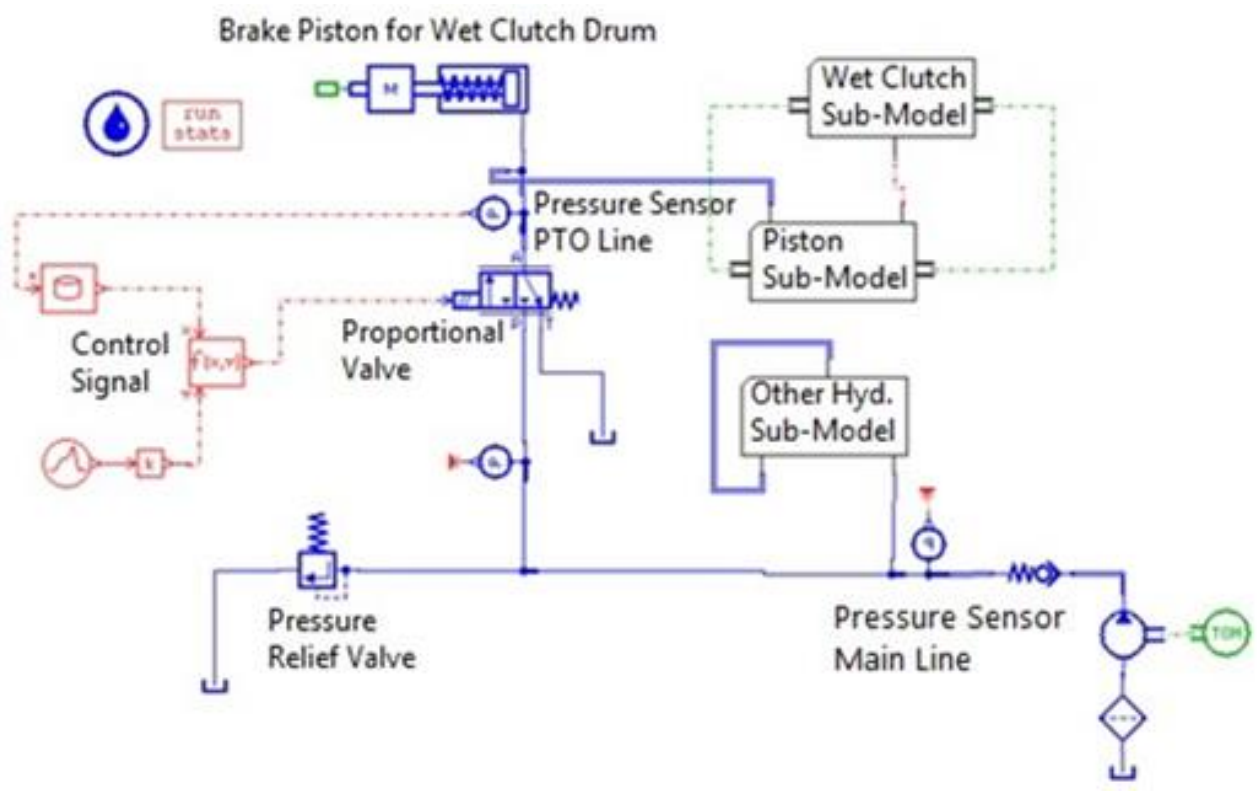

Fig. 3. 1-D Model of the wet clutch system constructed in Amesim

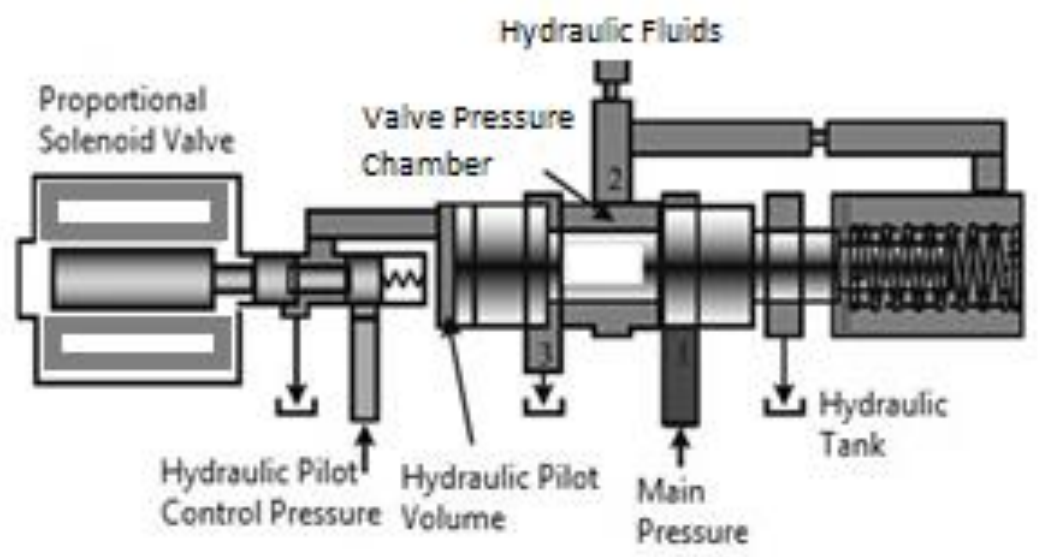

Fig. 4. Simplified schematic model of the proportional valve

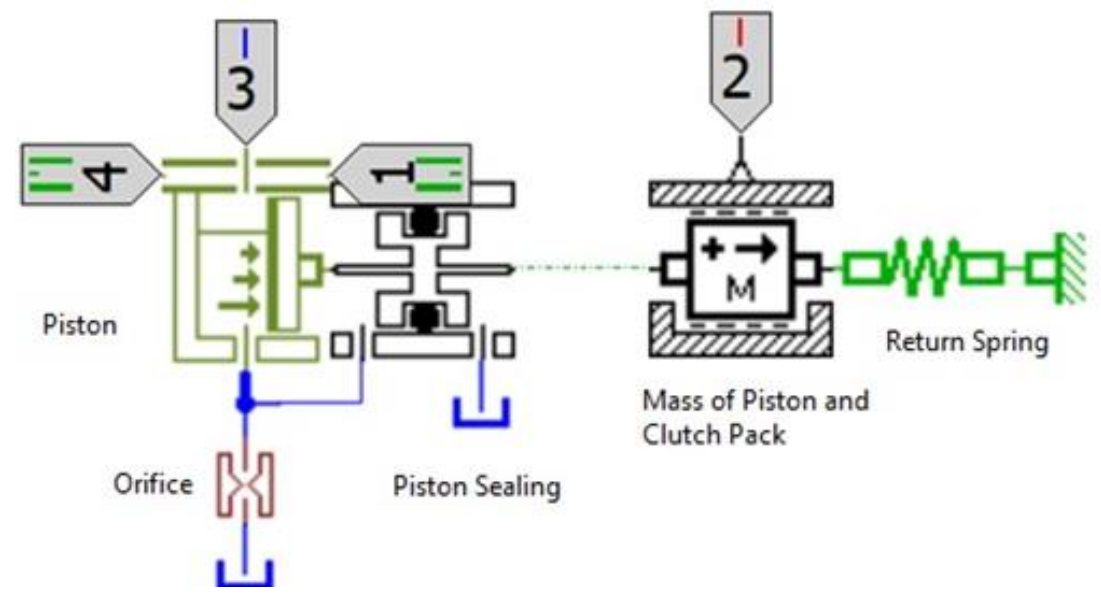

Fig. 5. Detailed piston model 
the oil volume $V_{o i l}(t)$, and the total piston volume $V_{p v}(t)$ must be greater than or equal to the oil volume.

$V_{p v 0} \leq V_{o i l}(t) \leq V_{p v}(t)$

The volume ratio $V_{f r}(t)$ is calculated by dividing the hydraulic fluid volume by the piston volume. $V_{f r}(t)=1$ indicates that the piston volume is filled with fluid.

\section{Calculation of the Piston Internal Pressure}

To examine the pressure balance on the inlet and outlet sides of the fluid entering the piston, the radial distance between the inlet and outlet ports is critical (Fig. 6). The pressure in the piston volume $\left(P_{c h}\right)$ is initially equal to the atmospheric pressure
$P_{a m b}$ since the oil pan is a breathing one, and it will remain so until the volume ratio is $V_{f r}=1$.

$P_{c h}=P_{a m b}$

When $V_{f r}=1$, the piston volume is calculated as;

$\frac{d}{d t}\left(P_{c h}\right)=\frac{B\left(P_{c h}\right) \cdot\left(q_{1}+q_{3}\right)}{v o l}$

The centrifugal pressure in the piston is calculated as;

$$
P_{\text {centri }}(r)=\frac{\rho}{2} \cdot\left(r^{2}-r_{\text {level }}^{2}\right) \cdot \omega^{2}
$$

where $\omega$ is the angular velocity of the piston, $\rho$ is the volumetric density of the transmission fluid, and $r_{\text {level }}$ is the distance (radius) of the oil level from the center.

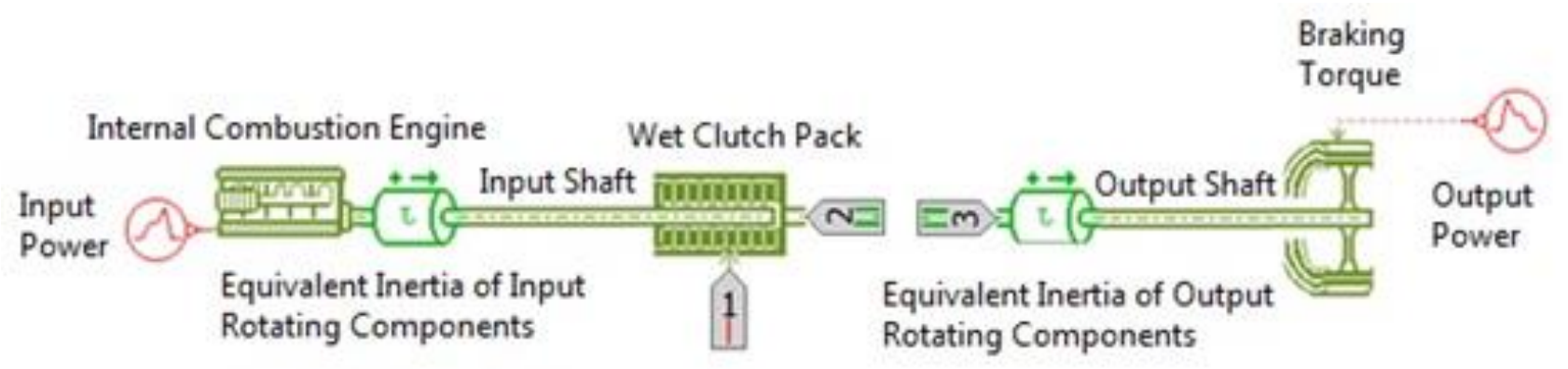

Fig. 6. Mechanical Model of Wet Clutch driven by ICE and retarded by the brakes

\section{Calculation of the Piston Force}

The force generated by the pressure on the effective area of the piston will be transmitted to the clutch pack to compress the clutch plates. The piston force can be calculated in different ways depending on the amount of fluid in the chamber and the piston position. When $r_{\text {level }}>r_{p}$, the piston force is $F_{p}=A_{P} \cdot P_{c h}$

where $F_{p}$ is the piston force, $A_{P}$ is the piston area.

If $r_{\text {level }}<r_{r}$;

$F_{p}=A_{P} \cdot P_{c h}+\frac{\pi \cdot \rho}{4} \cdot \omega^{2} \cdot\left(r_{p}^{4}-r_{r}^{4}-2 \cdot r_{\text {level }}^{2} \cdot\left(r_{p}^{2}-r_{r}^{2}\right)\right)$

Otherwise;

$F_{p}=A_{P} \cdot P_{c h}+\frac{\pi \cdot \rho}{4} \cdot \omega^{2} \cdot\left(r_{p}^{2}-r_{\text {level }}^{2}\right)^{2}$

\section{Modeling of the Piston Mass based on Damping Characteristics}

This piston mass acts on the clutch pack depending on the stiffness and damping coefficients. The damping coefficient of the wet clutch package, $R_{\text {pack }}$, is primarily present to find the force generated in the piston mass. The damping ratio $z$ is expressed by the stiffness coefficient $C_{\text {pack }}$ of the clutch package.

$R_{\text {pack }}=2 \cdot Z \cdot \sqrt{C_{\text {pack }} \cdot \operatorname{masS}}$
In the design, the piston pressure acts on the left side of the mass, while the spring force and the clutch pack force and the damping response force of the clutch pack are transmitted to the right side. Then the following equation is used to calculate the net force on the mass.

$F_{\text {net }}=F_{\text {left }}-F_{\text {right }}-F_{\text {pack }}-v_{1} \cdot R_{\text {pack }}$

where $v_{1}$ is the piston speed.

\section{Modeling of the Spring}

The function of the spring in the clutch pack is to ensure that the piston returns to its original position when pressure is equal to zero. The stiffness of this spring must be optimized for the case of high back pressure on the return line as well. A spiral spring is used, and the coefficient $\mathrm{k}$ is calculated as follows:

$k=\frac{G \cdot d^{4}}{8 D^{3} n_{a}}$

where $n_{a}$ is the number of coils, $G$ is the shear modulus of the steel, $D$ is the coil diameter, and $d$ is the wire diameter of the spring. The spring force can be calculated as;

$F_{y a y}=k \cdot x_{\text {comp }}$ 


\section{Clutch Model}

The clutch is physically made up of thrust plates and friction discs. According to the Coulomb friction model, the torque value of the clutch is modeled depending on the temperature variation. In this model, the input signal is transmitted as the piston output force. The piston force is transmitted as a normal force on the wet clutch pack. The limiting torque value that can be carried by the clutch pack, $T_{\max }$, can be calculated as:

$T_{\max }=\mu \cdot F_{\text {total }} \cdot R_{e f f} \cdot n p$

where $\mu$ is the friction coefficient, $F_{\text {total }}$ is the total normal force, $R_{e f f}$ is the effective clutch disc radius, and $n p$ is the total number of friction surfaces.

The following relation is proposed by many references to predict the effective clutch disc radius:

$R_{\text {eff }}=\frac{2}{3} \frac{\left(R_{\text {in }}^{3}-R_{\text {out }}^{3}\right)}{\left(R_{\text {in }}^{2}-R_{\text {out }}^{2}\right)}$

Here, $R_{\text {in }}$ and $R_{\text {out }}$ are the inside and outside radii of the friction discs, respectively.

The friction coefficient $\mu$ may be taken as constant, or it may be defined more accurately as a function of temperature and slipping (relative) velocity. In the proposed model, the coefficient of friction $\mu$ is modeled as a function of the temperature difference. The temperature difference $d T$ is calculated by transferring the mechanical power while the power loss rate $\left(P_{L, p e r}\right)$ briefly indicates the loss as a percentage. Multiplication of angular velocities of the clutches and the product of the transmitted torque $\left(T_{1}\left(\omega_{1}+\omega_{3}\right)\right)$ gives the total power loss.

$d T=\frac{P_{L, p e r} \cdot\left(T_{1}\left(\omega_{1}+\omega_{3}\right)+h \cdot(20-t e m p)\right.}{m \cdot C_{p}}$

where $h$ is the heat transfer coefficient, $m$ is the mass, and $C_{p}$ is the heat capacitance.

Depending on the temperature variation, the dynamic coefficient of friction $\mu(T)$ is supplied to the model from tabulated empirical data (Table 1).

Table 1. Variation of the friction coefficient as a function of temperature

\begin{tabular}{c|c}
\hline Temperature, $T \circ \mathbf{C}$ & Friction Coefficient, $\mu$ \\
\hline 0 & 0.2 \\
\hline 50 & 0.35 \\
\hline 100 & 0.45 \\
\hline 150 & 0.38 \\
\hline 200 & 0.35 \\
\hline 250 & 0.34 \\
\hline 300 & 0.38 \\
\hline 370 & 0.15 \\
\hline
\end{tabular}

The mechanical power generated by the ICE is connected to the pressure disc side of the wet clutch pack by the input shaft (Fig. 6). The friction plates are connected to the output shaft. A brake unit is added on the output shaft side, to generate braking torque and also to simulate the operation of the ICE under different loads.

\subsection{Hydraulic System}

The transmission fluid in the tractor gearbox is circulated within the hydraulic control system as well. Since the breather is located on the transmission housing, the pressure in the oil sump is assigned to the global variable $\mathrm{P}_{\mathrm{amb}}$; and, it is initially taken as $10^{-4} \mathrm{mBars}$.

The pump used in the proposed design is a fixed displacement external gear pump. The rotor displacement must be multiplied by the speed of the pump gear to achieve the nominal flow rate of a gear pump.

$q_{\text {nom }}=\frac{\Delta x \text { speed }}{1000}(\mathrm{lpm})$

The performance test results of the gear pump used in the system are shown in Table 2.

A check-valve is added to the model to ensure the safety of the pump by preventing damage by counter pressure. While the check-valve is modeled, force balance and flow fluid flow balance are taken into consideration. When calculating the force balance and how far the slide of the check-valve travels, the hydraulic damper area opens with the distance it moves, and the flow equation is calculated.

Table 2. Test data of the gear pump

\begin{tabular}{c|c|c}
\hline Parameter & Unit & Value \\
\hline Displacement & $\mathrm{cc}$ & 8 \\
\hline Rotational speed & $\mathrm{rpm}$ & 1500 \\
\hline Fluid flow rate (Unloaded) @ 30 bar & $\mathrm{lpm}$ & 11,84 \\
\hline Fluid flow rate (Loaded ) @ 176 bar & $1 \mathrm{pm}$ & 11,53 \\
\hline Volumetric efficiency, $\eta_{\mathrm{v}}$ & $\%$ & 97,38 \\
\hline Mechanical efficiency $\eta_{\mathrm{m}}$ & $\%$ & 90,97 \\
\hline Total efficiency, $\eta_{\mathrm{t}}$ & $\%$ & 88,59 \\
\hline
\end{tabular}

The opening pressure of the forced spring in the check-valve in the closing direction shows a hysteretic behavior.

The plunger position of the valve $x_{v}$ is calculated using the following equation:

$x_{v}=\frac{p_{\text {in }}-p_{\text {out }}-p_{\text {crack }}}{k_{\text {Vyay }}}$

where $p_{\text {in }}$ is check-valve inlet pressure, $p_{\text {out }}$ is check-valve outlet pressure, $p_{\text {crack }}$ is check-valve opening pressure, and $k_{V y a y}$ is the stiffness coefficient of the spring used in the 
check-valve. Then the flow rate through the valve is calculated as follows:

$q_{\text {out }}=x_{v} \cdot a_{\max }$

where $a_{\max }$ is the area corresponding to the given flow pressure drop in the model.

The task of the valve is to maintain constant pressure on the line. Port-P of the valve is pressurized by the pre-tensioned spring. Different approaches can be adopted to model the opening dynamics of the valve at Port-D, the user port. Static, 1 st order and 2 nd order dynamic forms are possible. In the firstorder system between the pressure and flow, the time constant needs to be defined. In the 2nd order model, the natural frequency and damping ratio of the valve are needed. Especially in valves with low frequency and high flow rate, a second-order analysis is more representative. However, depending on the rotational speed of the pump, the valve may resonate. Consequently, because the flow rate is relatively low in this case, a 1st order model is preferred, finding the time constant being more convenient.

Pressure reducing proportional valves (PPRV) have various applications, including cases in which load-dependent control is required, and the modulation ramp must be precisely adjusted. The hydraulic-pilot actuated valve controls the internal pressure dynamically by feeding the pressure on the user side back into the valve. Due to its dynamic response in wet clutch applications, it is possible to ramp the hydraulic pressure gently after the control volume is filled quickly by feeding a high peak current.

The working principle of the proportional valve can be explained as follows: In the absence of current on the valve solenoid, Port-P is closed, and the passage of the fluid to Port-C is blocked. The fluid in Port $\mathrm{C}$ can freely return to the $\mathrm{T}$-line (tank line). When the electrical current is on and increased, the valve slider $\mathrm{P}$ opens Port-C gradually, the pressure increases proportionally as the slider opens. When the slider starts to move, port-T closes, and the pressure is only transmitted to portC. When the valve slider remains constant at the desired pressure, the pilot pressure on the user's side generates a force opposite to the solenoid valve (electromagnetic) force as a support to the spring side, and the valve is maintained in balance.

The repeatability of the solenoid valve controlled by PWM is excellent. On the other hand, the hysteresis can be observed. The solenoid valve needs to be controlled with a current of $1500 \mathrm{~mA}$ to achieve approximately 23 bars on the user-side Port-C.

\subsection{Control System}

Simulation trials at different rates were carried out to find the optimum ramp of the control signal for the valve. The simulated ramping times include $5,6,7,8,9,10$ seconds. The control signal ramp determines the time angular velocities of the wet clutch discs and plates are equalized such that the required comfort level and durability are optimized. Every signal has the same fill-up characteristic. The time at which the first filling signal is received and the time needed for the signal ramp to reach the desired current value are the analyzed variables.

\section{Simulation Results}

Using the system model explained above, and the variables listed in Table 3 , the engagement process at $300 \mathrm{~N}-\mathrm{m}$ load was simulated for 40 seconds (Fig. 7). Accordingly, the output shaft reaches the target speed in 10 seconds. Input and output shaft velocities, clutch and mainline pressures, piston force, displacement, speed and acceleration, centrifugal force on the piston, spring force on the clutch, stiffness and damping coefficients, Coulomb friction coefficient, the fluid flow and pressure changes at the proportional valve ports are predicted as functions of time.

Variation of the piston force follows the trend of piston pressure and stabilizes at $26,5 \mathrm{kN}$ in 13 seconds and with a steady oscillation of $+/-0.5 \mathrm{kN}$. That is, the piston force reaches steady state 3 seconds after the output shaft angular velocity.

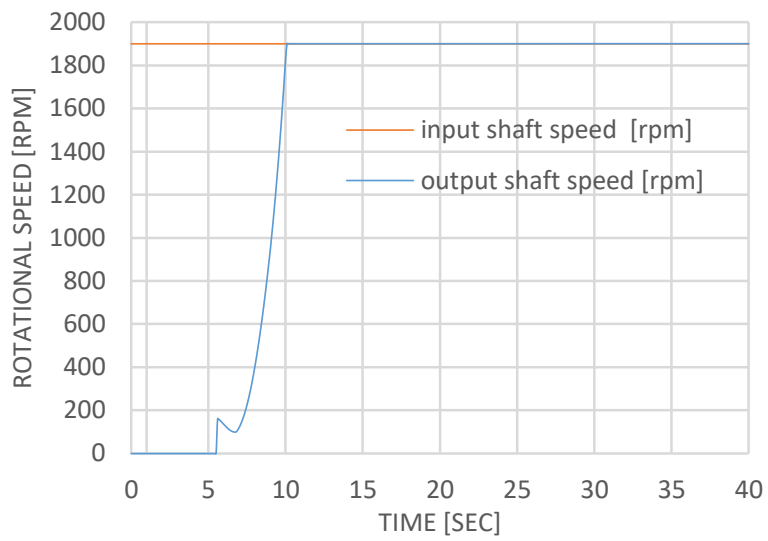

Fig. 7. Variation of the input and predicted output shaft speeds versus time

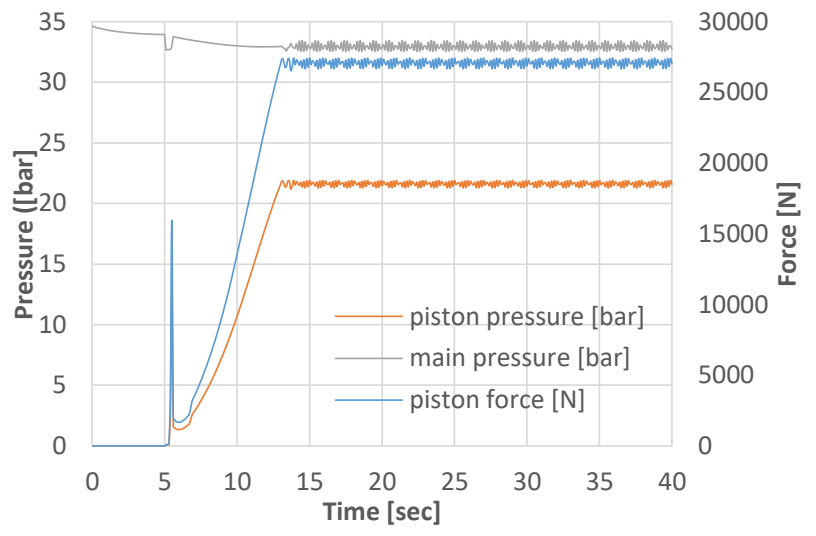

Fig. 8. Predicted variation of the clutch and mainline pressure (left axis) and the piston force (right axis) 
Table 3. List of simulation variables

\begin{tabular}{|c|c|c|}
\hline Description & Unit & Value \\
\hline Moment of inertia - discs side & $\mathrm{kgm}^{2}$ & 0.1 \\
\hline Initial linear velocity of the piston & $\mathrm{m} / \mathrm{s}$ & 0 \\
\hline Clutch pack damping ratio & & 0.25 \\
\hline Piston mass with $1 / 3$ return spring-mass & $\mathrm{kg}$ & 0.552 \\
\hline Leakage flow - active side & $1 \mathrm{pm}$ & 1 \\
\hline $\begin{array}{l}\text { Piston seal thickness at inside diameter } \\
\text { - active side }\end{array}$ & $\mathrm{mm}$ & 2.3 \\
\hline $\begin{array}{l}\text { Piston seal thickness at the } \\
\text { outer diameter - active side }\end{array}$ & $\mathrm{mm}$ & 3 \\
\hline Index of hydraulic fluid & & 0 \\
\hline Piston inside diameter - active side & $\mathrm{mm}$ & 50.825 \\
\hline Initial rotary speed port $3-$ plates side & $\mathrm{rpm}$ & 0 \\
\hline Initial rotary speed port $2-$ discs side & $\mathrm{rpm}$ & 1000 \\
\hline Piston outside diameter - active side & $\mathrm{mm}$ & 135.38 \\
\hline Piston outside diameter & $\mathrm{mm}$ & 135.38 \\
\hline Ambient pressure & bar & 0.0001 \\
\hline Fluid entry diameter - active Side & $\mathrm{mm}$ & 60.27 \\
\hline Moment of inertia - plates side & $\mathrm{kgm}^{2}$ & $0.001+1$ \\
\hline Piston inside diameter & $\mathrm{mm}$ & 50.76 \\
\hline Initial linear displacement of the piston & $\mathrm{mm}$ & 0 \\
\hline Initial pressure-active side & bar & 0.0001 \\
\hline Initial speed & $\mathrm{rpm}$ & 1900 \\
\hline Initial torque & $\mathrm{Nm}$ & 300 \\
\hline
\end{tabular}

Fig. 9 shows the predicted fluid flow rates at the piston entry and exit ports. These curves are almost symmetrical at +5 and $-5 \mathrm{lpm}$; however, the flow rate at the exit is much less oscillatory. The PWM controlled proportional valve is responsible for the apparent oscillations of the inlet flow rate. The dampened oscillations on the exit side are due to the mass and friction damping characteristics of the mechanical elements of the clutch. The piston displacement, which is an integrated quantity shown on the same plot, gives a flat curve after about 13 seconds without any variation.

Fig. 10 shows the simulated variation of piston speed and acceleration as functions of time. These curves are supplementary to the piston displacement curve above, and they show that the PWM control produces a very oscillatory piston acceleration behavior. However, being integrated over time, much smaller oscillations are seen on piston velocity, and almost no oscillations exist in displacement. These curves prove the consistency of the mathematical model and show the readiness of the system for experimental validation.

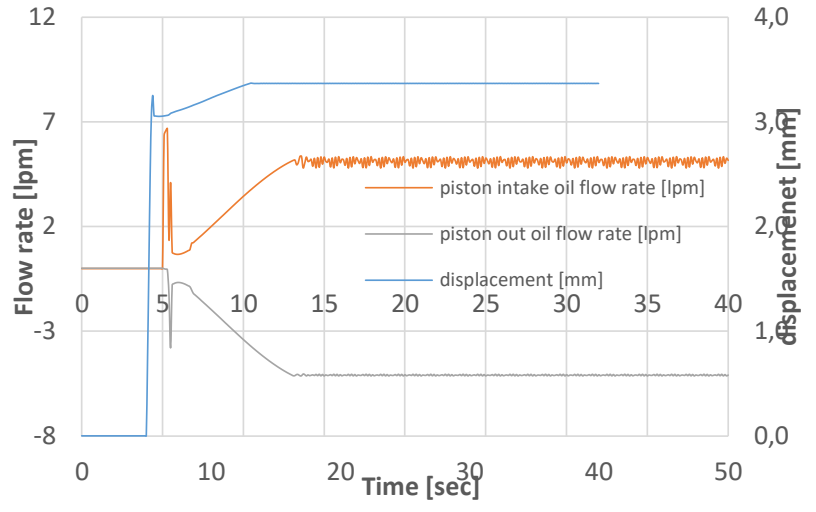

Fig. 9. Simulated behavior of the fluid flow rate (left axis) and piston displacement (right axis) vs. time

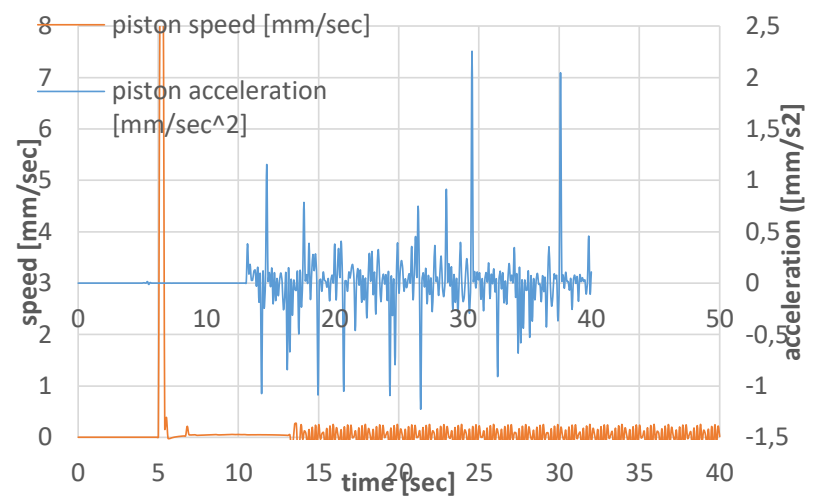

Fig. 10. Simulated variation of piston speed and acceleration vs. time

As shown in Fig. 11, the average fluid flow rate at Port-T (tank line) becomes approximately equal to $0(-0 /+0.8) \mathrm{lpm}$ in 13 seconds, because the tank is a breathing one. The flow rate on the user line (Port-A) and the flow rate on the piston line (Port-P) are $5.5(-1.5 /+0)$ and $-5.5(-0 /+0.7) \mathrm{lpm}$. The timing of the oscillations are coincident such that summing the oscillations at Port-T and Port-P, the ones at Port-A are balanced. Since the valve slider is in motion due to a continuous PWM signal, the flow also oscillates with the same characteristic as the pressure (Fig. 8).

The initial temperature of the fluid in the hydraulic system is taken as $40^{\circ} \mathrm{C}$ in both simulations and tests. The behavior of the hydraulic control elements and the clutch pack at 60,80 , and $100^{\circ} \mathrm{C}$ are also simulated. As the output of simulations, the piston pressure and speed versus time are examined. Fig. 12 shows that as the temperature increases, the clutch pressure at steady-state increases slightly. It is seen that the pressure that stabilizes at steady-state is approximately 21.5 bars at $40^{\circ} \mathrm{C}$ while it reaches 22.5 bars at $100^{\circ} \mathrm{C}$.

\section{Experimental Verification}

\subsection{Test Method and Set-up}

The effect of hydraulic fluid temperature on the behavior of the wet multi-plate clutch is observed on the input shaft and output 


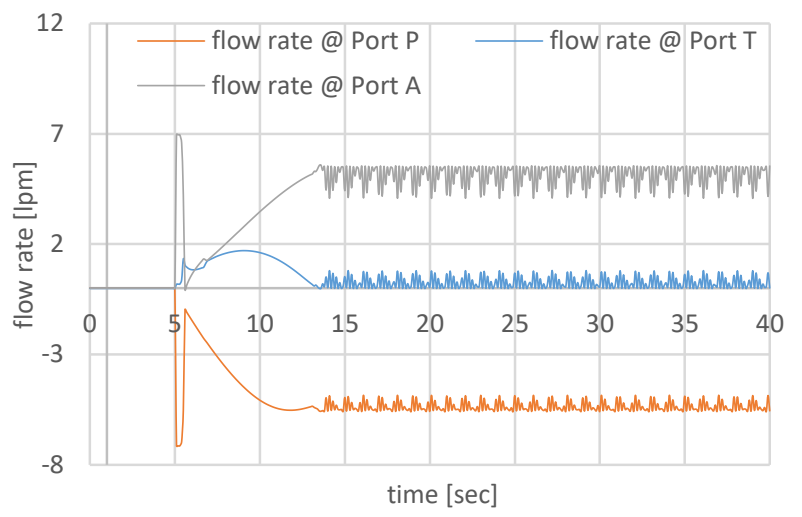

Fig. 11. Simulated variation of fluid flow rate at the valve ports vs. time

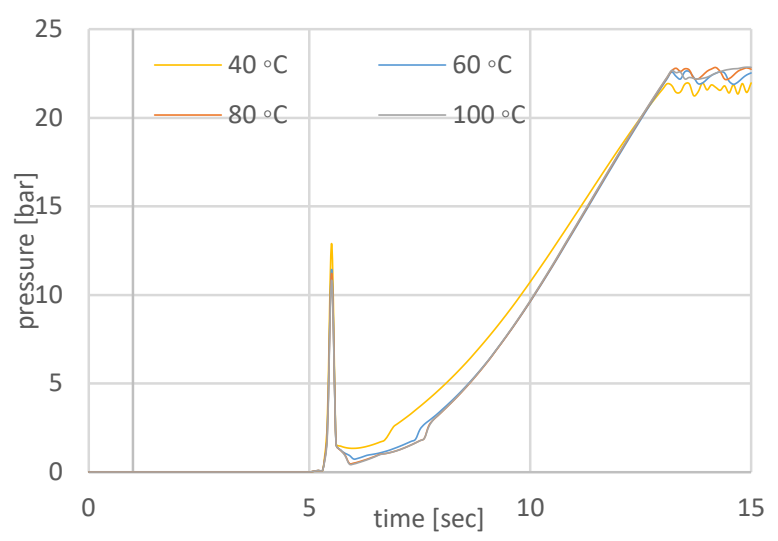

Fig. 12. Simulated variation of the clutch pressure at various temperature levels

shaft speeds, the hydraulic mainline pressure, and the pressure of the hydraulic oil in the hydraulic clutch pack. The tractor was loaded with a tail dynamometer under 300 and $600 \mathrm{~N}$-m torque at $1,900 \mathrm{rpm}$ (Fig. 13). After selecting the parameters to be measured, and the measurement points, instrumentation of the hydraulic and mechanical components was completed. A data acquisition system (IMC Cronoflex), with frequency data ranging from $2 \mathrm{kHz}$ to $1 \mathrm{~Hz}$ was used. The engine rotational speed was recorded from the alternator side by counting impulses.

A speed sensor measured PTO speed with a unique gear geometry mounted on the shank, and the impulses were converted and recorded (Fig. 14). Pressure was measured at three different points on the mainline, at the clutch, and after the control valve (Fig. 15), and a PT-100 sensor measured the fluid temperature in the oil pan.

\subsection{Test Results}

Tests were started at 1,900 rpm engine speed, and after loading at 300 and $600 \mathrm{~N}-\mathrm{m}$ torque, steady-state was reached at 1,700 and 1,600 rpm, respectively. The recorded data was processed through necessary filtering operations and cleaned from noise

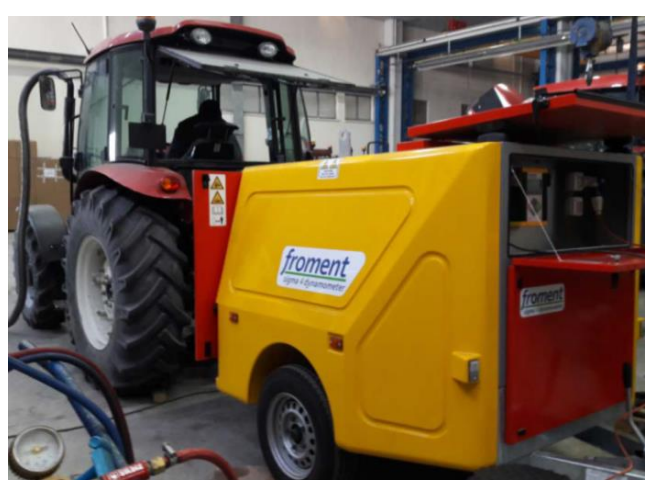

Fig. 13. Test set-up: tractor tail-shaft connection of the dynamometer
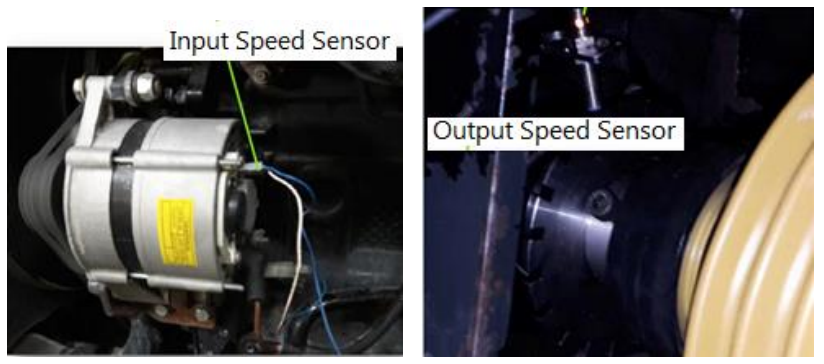

Fig. 14. The motor speed sensor (upper) and the tail shaft speed sensor (lower)

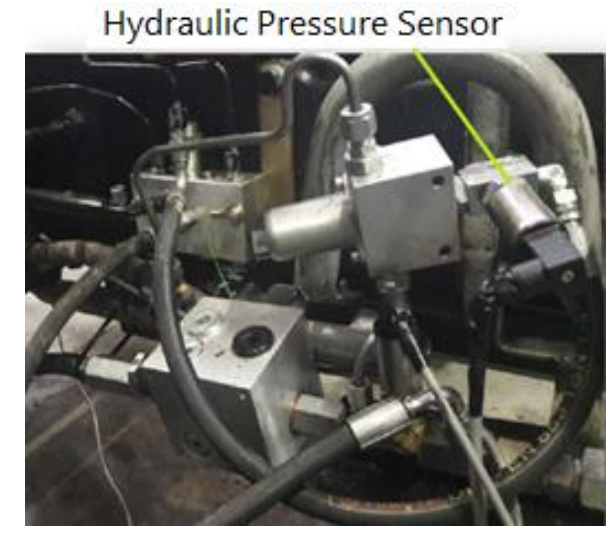

Fig. 15. Connection of the pressure sensor

(Fig. 16). When the hydraulic pressure is applied to the clutch body, the output shaft speed increases parallel to the increase in the pressure, and the output shaft speed gets equal to the input shaft speed.

The behavior of the ICE cannot be simulated precisely. Because of that, a difference in steady-state speed between measured (Fig. 16) and simulated (Fig. 7) results can be observed.

The clutch and mainline pressures (after the pressure control valve) versus time are shown in Fig. 17. The pressure curves in the 300 and $600 \mathrm{~N}-\mathrm{m}$ tests have similar characteristics. When the valve is opened by the control signal to deliver oil to the clutch body, the fluid quickly fills all hydraulic oil lines, pistons, and actuators. Thus it overcomes the inertia and activates wet grip in 10 seconds. Next, an instantaneous decrease of 2 bars is 


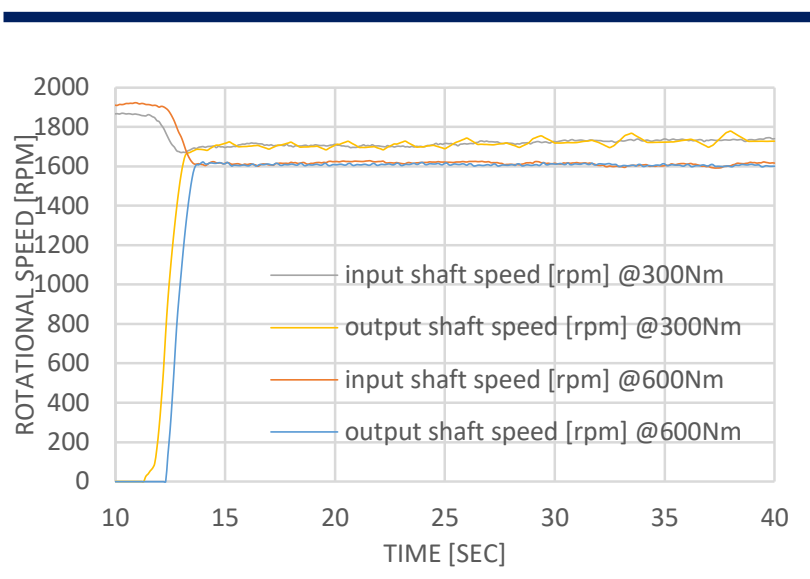

Fig. 16. The input and output shaft speeds (under 300 and $600 \mathrm{~N}-\mathrm{m}$ torque)

measured, as a new volume is formed for the pressurized oil when the mainline pressure signals the controller. The 10-

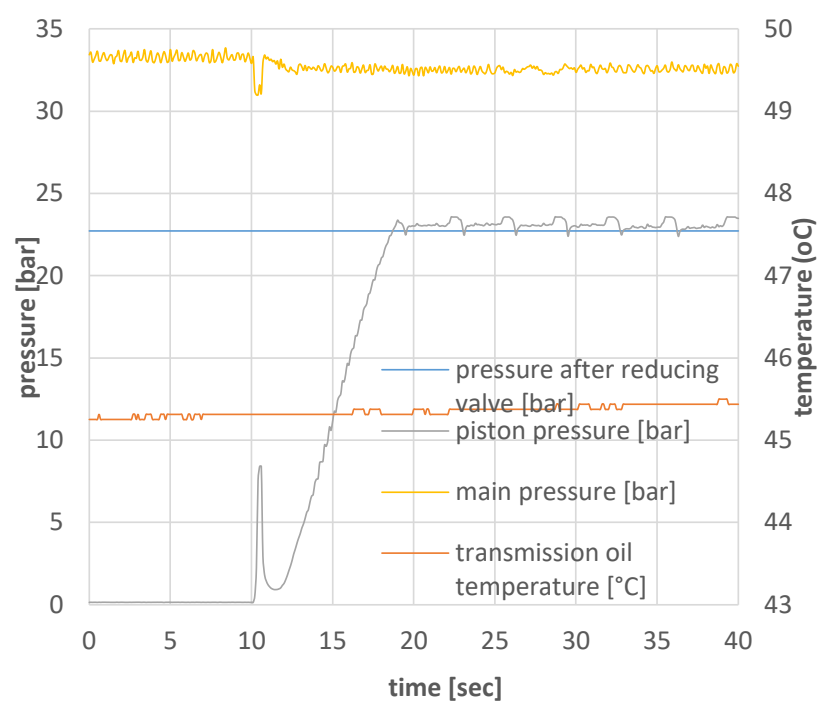

Fig. 17. Behavior of pressure and temperature vs. time under 300 (left) and $600 \mathrm{~N}-\mathrm{m}$ load (right)

A pressure relief valve is used to maintain the mainline pressure. There is a difference of 0.3 bars between the simulation and the test results. The over-prediction is approximately $1 \%$. Besides, the mathematical model is stiffer than the experimental set-up, giving relatively less oscillations. These minor differences are primarily due to the fluid and other pressure losses cannot be modeled precisely (Fig. 19). It is seen that the downward trends in the simulation and test results are similar due to the transfer of oil to the wet clutch volume, which is a new control volume at the mainline pressure after the 5th second of the signal for the proportional valve to be activated.

\section{Conclusions}

In this article, the control of a wet clutch pack using a proportional second signal is applied, and the proportional valve slider moves to allow the pressure to pass quickly to the opposite side, then closing the user side to increase the pressure through the programmed modulation ramp. Meanwhile, the oil temperature remains constant at $36.5^{\circ}$ and $45^{\circ} \mathrm{C}$, during loading at 300 and $600 \mathrm{~N}-\mathrm{m}$, respectively.

When the test and simulation results of the clutch pressure ramp are compared as in Fig. 18, the output curve of the highest pressure curve after the triggering is found steeper in the simulation than the measured one. Besides, reaching the maximum pressure during the test takes about 3 seconds longer than simulation, and the average clutch pressure is 2.5 bar ( 10\%) underpredicted. The predicted oscillations after 13 seconds show a sinusoidal nature, while the measure oscillations indicate behavior of a more complex system. These insignificant differences may be due to the simplifications in the 1-D model. Yet, the comparison proves the strength of the system model in the design and tune-up of new wet clutch applications.

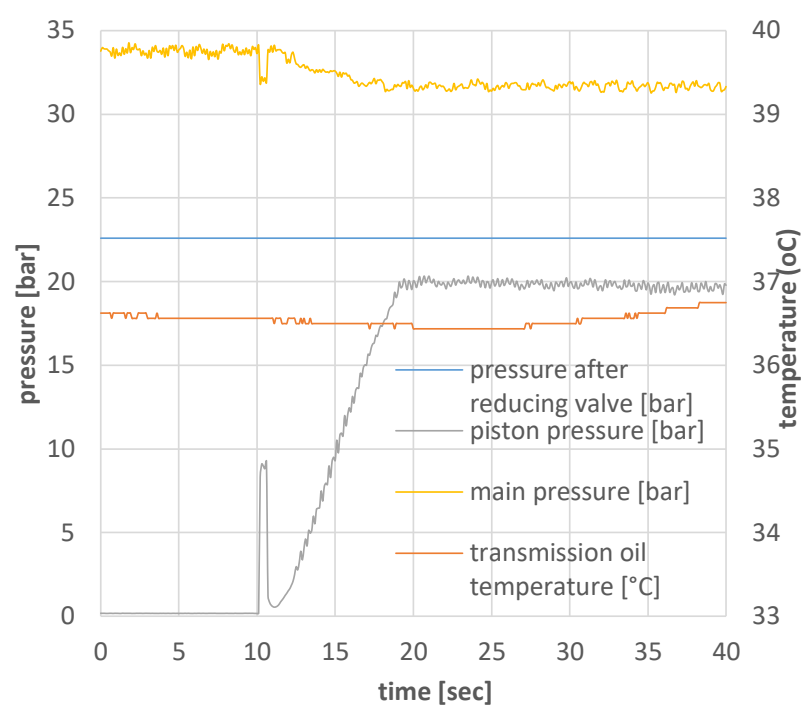

valve in the power take-off unit of an agricultural tractor is investigated. Simulations using a one-dimensional mathematical model led to an optimized system validated on an instrumented test tractor. The validity of the model is discussed by comparing the simulation and test results.

Variables, including the piston speed, input, and output oil flow rate, which are difficult to be measured accurately, are interpreted only using the simulation results. Among the measured parameters, the clutch pressure increase due to the intended modulation ramp was predicted within $10 \%$, and the mainline pressure drop was predicted within $1 \%$. These results enable much less trial-and-error on new designs of the drive-train, wet clutch, and controller. Indeed, the model can be improved further by including the ICE so that the loss of tail shaft and hydraulic pump speed could be predicted more accurately under loading. Pressure drop on the hydraulic circuit 
may also be predicted better by including geometric details of the tubing, hoses, and fittings. In the system, the dither frequency is provided by the electronic control card, and stable triggering of the valve during the long-term operation is crucial for valve reliability. Detailing the controller, proportional valve, leakage, hysteresis, valve response models, valve reliability analyses can be performed more accurately.

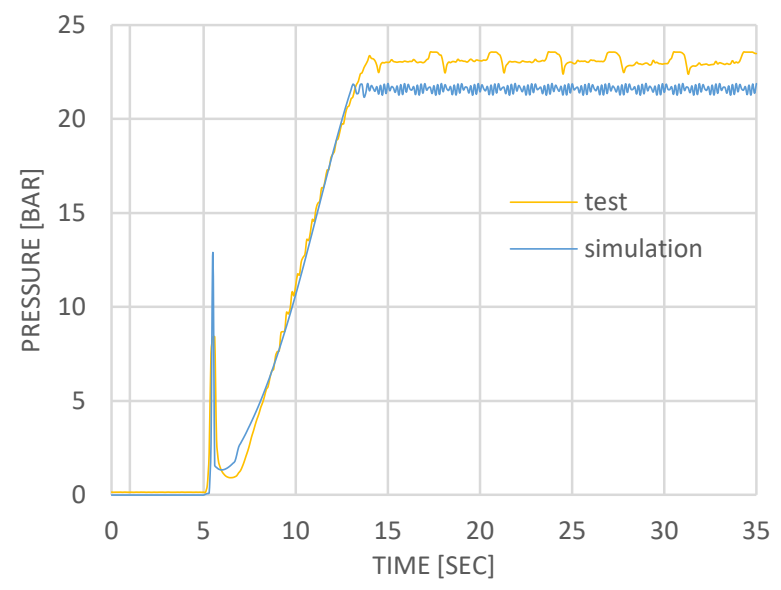

Fig. 18. Measured and predicted clutch pressure vs. time.

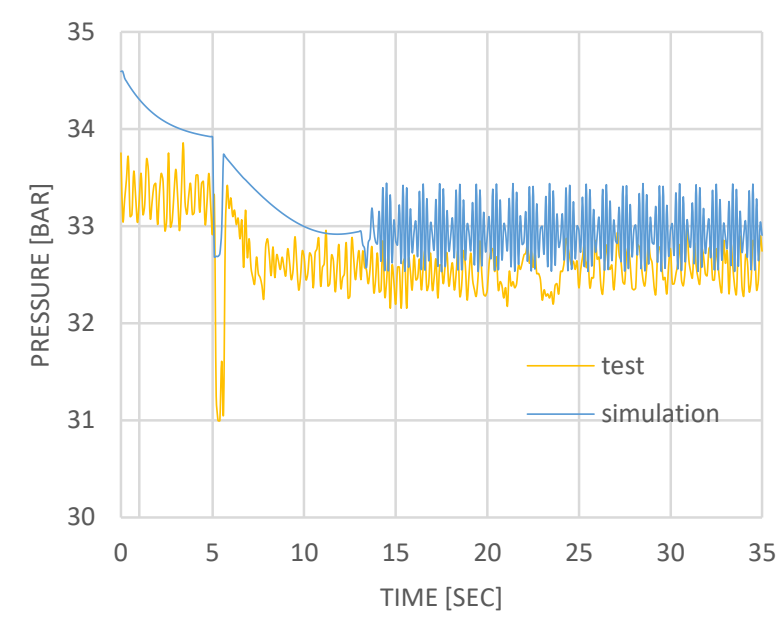

Fig. 19. Measured and predicted mainline pressure vs. time.

\section{Acknowledgements}

The investigation presented in this article was internally supported by TÜMOSAN Engine and Tractor Corp. Gratitude goes to Mr. Cihat Günay, Mr. Arda Alpan, and Mr. Kurtuluş Öğün as well as many other colleagues working in the group.

\section{Conflict of Interest Statement}

The authors declare that there is no conflict of interest.

\section{CRediT Author Statement}

Ali Evren Yel: Design, modeling, analysis, testing and validation; Writing-the original draft as a Master's thesis conducted at
Yildiz Technical University, Haydar Livatyalı: Conceptualization, Supervision, Translation of the original draft to English, Editing.

\section{References}

[1] Naunheimer H, Bertsche B, Ryborz J, Novak W. Automotive Transmissions, 2nd Ed. Springer-Verlag, Berlin. 2011

[2] Balau AE, Caruntu CF, Lazar C. Simulation and Control of an Electro-hydraulic Actuated Clutch Mechanical Systems and Signal Processsing. 2011; 25: 1911-1922

[3] Fischer R, Küçükay F, Jürgens G, Najork R, Pollak B. The Automotive Transmission Book, Springer, Switzerland. 2015.

[4] Venu MKK. Wet Clutch Modelling Techniques: Design Optimization of Clutches in an Automatic Transmission M.Sc. Thesis Chalmers Univ. of Technology, Göteborg, Sweden. 2013.

[5] Küçükay F, Bock C. Geregelte Wandlerkupplung für den neuen 7er von BMW. ATZ. 1994; 96:690-697

[6] Meng F, Chen H, Zhang T, Zhu, X. Clutch Fill Control of an Automatic Transmission for Heavy-duty Vehicle Applications Mechanical Systems and Signal Processing. 2015; 64-65: 16-28

[7] Park YN, Kim DC, Park SJ. Delayed Operation Characteristics of Power Shuttle According to Hydraulic Oil Temperature in the Hydraulic Circuit of Agricultural Tractor J of Biosystems Engineering. 2014; 40: 95-101

[8] Morselli R, Zanasi R, Sereni E, Bedogni E, Sedoni E. Modeling and Control of Wet Clutches by Pressure Control Valves Proc. of IFAC Advances in Automotive Control Salerno Italy. 2004.

[9] Dutta A, Depraetere B, Ionescu C, Pinte G, Swevers, J, Keyser, RD. Comparison of Two-level N-mPC and ILC Strategies for Wet-clutch Control, Control Engineering Practice. 2013; 22: 114-124.

[10]Raikwar S, Tewari VK, Mukhopadhyay S, Verma RB, Rao MS. Simulation of Components of a Power Shuttle Transmission System for an Agricultural Tractor Computers and Electronics in Agriculture. 2015; 114: 114-124

[11]Kim DC, Kim KU, Park Y J, Huh, JY. Analysis of Shifting Performance of Power Shuttle Transmission J of Terramechanics. 2006; 44: 111-112

[12]Dutta A, Zhong Y, Depraetere B, Vaerenbergh KV, Ionescu C., Wyns B, Pinte, Nowe A, Swevers J, Keyser RD. Model-Based and Model-Free Learning Strategies for Wet Clutch Control. Mechatronics. 2014; 24:1008-1020.

[13]Zhanling JI, Yunhua LI, Dong S, Zhang P, and Yunze LI. Elastoplastic Finite Element Analysis For Wet Multidisc Brake During Lasting Braking. Thermal Science. 2015; 19:2205-2217.

[14]Walker PD, Zhu B, Zhang N. Nonlinear Modeling and Analysis of Direct Acting Solenoid Valves for Clutch Control. Journal of Dynamic Systems, Measurement and Control. 2014; 136:051023-2.

[15]Watson M, Byington C, Edwards D, Amin S. Dynamic Modeling And Wear-Based Remaining Useful Life Prediction of High Power Clutch Systems, Tribol Trans. 2005; 48(2):208-217.

[16]SimCenter Amesim 2019.1. Software Fact Sheet: Speeding Up System Simulation Processes. Siemens Product Lifecycle Management Software Inc. 2019. 